\title{
Distribution pattern of the snail intermediate host of schistosomiasis japonica in the Poyang Lake region of China
}

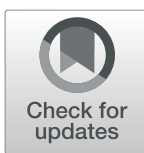

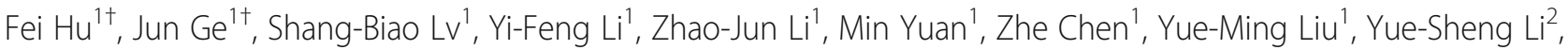
Allen G. Ross ${ }^{3}$ and Dan-Dan Lin ${ }^{1 *}$

\begin{abstract}
Background: With the closure of the Three Gorges Dam in 2003 the hydrology of Poyang Lake was altered dramatically leading to significant changes in the environment. In order to assess the impact on schistosomiasis this study assessed the spatial and temporal patterns of the snail intermediate host, Oncomelania hupensis in the Poyang Lake tributaries. The results of the study have important implications for future snail control strategies leading to disease elimination.

Methods: The marshland area surrounding Poyang Lake was divided randomly into $200 \times 200 \mathrm{~m}$ vector grids using ArcGIS software, and the surveyed grids were randomly selected by the software. The snail survey was conducted in each selected grid using a survey frame of $50 \times 50 \mathrm{~m}$ with one sideline of each grid serving as the starting line. No less than ten frames were used in each surveyed grid with Global Positioning System (GPS) recordings for each. All snails in each frame were collected to determine infection status by microscopy. Altitude data for all frames were extracted from a lake bottom topographic map in order to analyze the average altitude. All snail survey data were collected and statistically analyzed with SPSS 20.0 software in order to determine the difference of the percentage of frames with living snails and mean density of living snails in different regions of Poyang Lake. The altitude of the snail-infested marshlands and snail dens were subsequently identified.

Results: A total of 1159 potential snail sampling grids were surveyed, of which 15231 frames $\left(0.1 \mathrm{~m}^{2} /\right.$ frame $)$ were investigated. 1241 frames had live Oncomelania snails corresponding to $8.15 \%$ of the total number of frames. The mean density of living snails was $0.463 / 0.1 \mathrm{~m}^{2}$ with a maximum of 57 snails per frame. The percent of frames with snails in the southern sector (8.13\%) of Poyang Lake did not differ statistically from the north (8.21\%). However, the mean density of live snails in the northern sector $\left(0.164 / 0.1 \mathrm{~m}^{2}\right)$ of the lake was statistically higher $(F=6.727 ; P=0.010)$ than the south $\left(0.141 / 0.1 \mathrm{~m}^{2}\right)$. In the south of the lake, the elevation of snail-inhabited marshland ranged between $11-16 \mathrm{~m}$, and could be further subdivided into two snail-concentrated belts at 12-13 m of elevation and 15-16 $\mathrm{m}$ of elevation respectively. In the north of the lake, the elevation of snail-inhabited marshland ranged between 9-16 $\mathrm{m}$ with the elevation of 12-14 $\mathrm{m}$ being the snail-concentrated zone.

(Continued on next page)
\end{abstract}

\footnotetext{
* Correspondence: jxlindandan@163.com

Fei Hu and Jun Ge shared first authorship.

${ }^{1}$ Jiangxi Provincial Institute of Parasitic Diseases, No. 239, First Gaoxin Rd.,

Gaoxin District, 330096 Nanchang, Jiangxi Province, People's Republic of

China

Full list of author information is available at the end of the article
}

(C) The Author(s). 2019 Open Access This article is distributed under the terms of the Creative Commons Attribution 4.0 International License (http://creativecommons.org/licenses/by/4.0/), which permits unrestricted use, distribution, and reproduction in any medium, provided you give appropriate credit to the original author(s) and the source, provide a link to the Creative Commons license, and indicate if changes were made. The Creative Commons Public Domain Dedication waiver (http://creativecommons.org/publicdomain/zero/1.0/) applies to the data made available in this article, unless otherwise stated. 


\begin{abstract}
(Continued from previous page)
Conclusions: The elevation of snail-infested marshlands in the Poyang Lake region ranged from 9 to $16 \mathrm{~m}$. The snail distribution and habitat has moved north of the lake and to a lower altitude due to changes in the water level post dam closure. Based on the current geological features of the snail habitant focused mollusciciding should occur in snail dense northern regions with frequent bovine and human traffic. Targeting these identified 'hotspots' of transmission will assist in elimination efforts.
\end{abstract}

Keywords: Schistosomiasis, China, Poyang Lake, Oncomelania hupensis, Snail control, GIS mapping, Hotspot, Disease elimination

\section{Multilingual abstracts}

Please see Additional file 1 for translations of the abstract into the five official working languages of the United Nations.

\section{Background}

Scistosomiasis is considered a major public health in China and one of the diseases targeted for elimination [1]. Oncomelania hupensis, the sole intermediate host of Schistosoma japonicum in China, is vital for disease transmission. After more than 60 years remarkable achievements have been made in terms of schistosomiasis control in the People's Republic of China [2]. In 2015 China obtained the goal of schistosomiasis transmission control at the national level, and in five provinces/autonomous regions/municipalities (e.g., Shanghai, Zhejiang, Kuangtong, Fujian and Guangxi) the disease had been eliminated, while in Sichuan Province, schistosomiasis transmission has been interrupted [3].

Various measures of snail control play an important role in the global control of schistosomiasis and contribute to the great achievements that have been made in China to date. According to recent statistics the area of snail habitat nationally has decreased by $75 \%$ from 14.32 billion $\mathrm{m}^{2}$ in the 1950s to 3.57 billion $\mathrm{m}^{2}$ in 2016. The marshlands in the Poyang and Dongting lakes account for $95 \%$ of the present snail habitat [4]. The lake regions represent the last strong hold of the disease where the water levels cannot be adequately controlled and the snail intermediate host is widely distributed. The existence of vast snail habitats is a key factor that hampers the progress of schistosomiasis elimination in China and is one of the risks for periodic rebounds in disease transmission [5-8].

Jiangxi province is one of remaining highly endemic provinces in China. It has $0.787-0.810$ billion $\mathrm{m}^{2}$ of snail-infested areas of which marshlands account for $97 \%$. The vast majority of snails currently distributed in the Poyang Lake region are in newly developed snail environments post closure of the Three Gorges Dam [4, 9]. The human prevalence is less than $5 \%$ in formerly highly endemic communities. Exposed populations live adjacent to the marshlands with occupational risks associated with fishing, farming, and washing clothes.

The vast marshlands of Poyang Lake are historically suitable for snail breeding. After closure of Three Gorges Dam in 2003 the hydrology in Poyang Lake has changed dramatically. The results of a water level surveillance survey conducted during the period of 1973-2011, at the Hukou Hydrological Station, showed that the mean water level of the lake was $13.1 \pm 0.9 \mathrm{~m}$ before 2005 and decreased to $11.8 \pm 0.9 \mathrm{~m}$ after 2006 [10]. At Xinzi Hydrological Station, the number of days when the water level was higher than $13 \mathrm{~m}$ has reduced, while increased when the water level was lower than $11 \mathrm{~m}$. This indicates that lower water levels are coming earlier in the year and that the dry season is more prolonged [11, 12]. It has also become apparent that the distribution of snails and their habitats have changed due to lower water levels post closure of the dam [13]. Given the lack of information on the current temporal and spatial patterns of the intermediate host of schistosomiasis in the Poyang Lake region we carried out an environmental study in order to determine the distribution of Oncomelania hupensis in the marshlands surrounding Poyang Lake. With the development of the Global Positioning System (GPS), Geographic Information System (GIS) and spatial statistics, this has provided new and effective tools to explore the relation between Oncomelania snails, schistosomiasis, and the natural environment [14-17]. In this study, we specifically investigated the distribution of Oncomelania snails in the Poyang Lake region using GIS and GPS in order to ascertain the dynamic changes in snail distribution patterns at different elevations in the marshlands and to further define the snail habitat. The outcomes are important for national integrated schistosomiasis control strategies leading to disease elimination.

\section{Methods}

\section{Study area}

The study was conducted in the Poyang Lake region of China which is situated in northern sector of Jiangxi Province [18]. It lies in a structural depression south of the Yangtze River with the coordinates of 
$28^{\circ} 11^{\prime}-29^{\circ} 51^{\prime} \mathrm{N}$, and $115^{\circ} 49^{\prime}-116^{\circ} 46^{\prime} \mathrm{E}$. It is fed by various rivers from Jiangxi, the most important being the Gan River, Wu River, Xin River, and Xiu River. Poyang Lake, the largest lake in China, drains into the Yangzte River at Hukou. The lake is a seasonal impounding and releasing lake, and the size of the lake between flood and dry season varies greatly every year from less than $1000 \mathrm{~km}^{2}$ in winter to more than $3000 \mathrm{~km}^{2}$ in summer $[19,20]$. In summer as the water level rise the marshlands become submerged. In winter flood waters recede and the covered marshlands appear once again. As shown in Fig. 1, the lake is divided into two sections bounded by Songmen Mountain. The northern section is the waterway to the Yangzte River. The much larger southern section is main lake body [21]. There are three types of marshlands: sand land, mud land, and grass land, with $3130 \mathrm{~km}^{2}$ of total area and $10-16 \mathrm{~m}$ of elevation. There are few sand lands found at lower elevation and mainly located on both sides of river ways. The number of mud lands is greater and their elevations are below $12 \mathrm{~m}$. The grass lands are primarily located in deltas where rivers enter the lake at elevations of 12-15 m [22] (Fig. 1).

\section{Sampling grids}

The spatial map of the snail-infested marshlands was established using ArcGIS (10.2, ESRI, RedLands, USA) with WGS-84 geographic coordinate system and Transverse Mercator projection coordinate system [23]. $200 \times 200 \mathrm{~m}$ vector grids were created on the spatial map of marshlands through Hawth's Tools in ArcGIS software, and the surveyed grids were randomly selected by the software. The formula for calculating grid sample size was $n=\mathrm{Z}^{2} \mathrm{P}(1-\mathrm{P}) / \mathrm{e}^{2}$, with $\mathrm{e}=0.03, \quad P=0.4713$ and $\mathrm{Z}=1.96$ (data came from average density of living snails in surveillance locations of the province in 2014) [24]. Longitude and latitude center points for each sample grid were derived, and the database of sample grids was established according to the county-level administrative divisions.

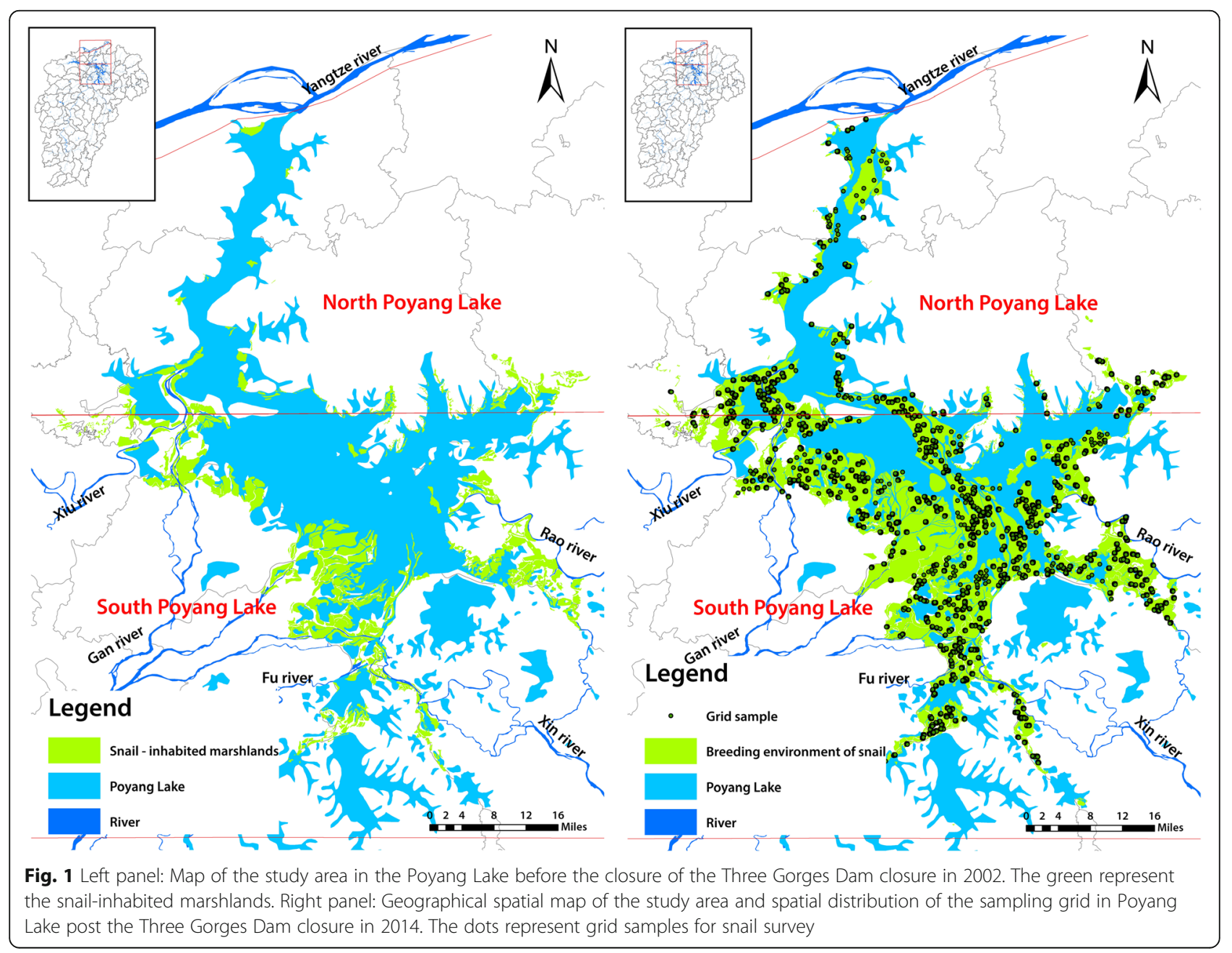


There were a total 62340 grids created for the marshlands of Poyang Lake, of which, 37754 grids were selected as a valid sample when its area was above $24000 \mathrm{~m}^{2}$ in more than half the area of each grid. There are 31207 in the south sector and 6547 valid grids in the north sector of Poyang Lake, respectively. 1159 grids were randomly selected for the Oncomelania snail survey, accounting for $3.07 \%$ of the total valid grids, with 949 grids in the south and 210 grids in the north (Figs. 1 and 2).

\section{Field survey}

The field survey was conducted in 2015 and 2016. Each selected grid was surveyed for snails with taking one side of each grid as the starting line. In each grid one survey frame of $0.1 \mathrm{~m}^{2}$ was set up within a $50 \mathrm{~m} \times 50 \mathrm{~m}$ area. There were 25 spots in each grid that were surveyed. However, some spots were submerged in water but no less than ten spots were obtained. All snails in each frame were collected and the GPS coordinates of each

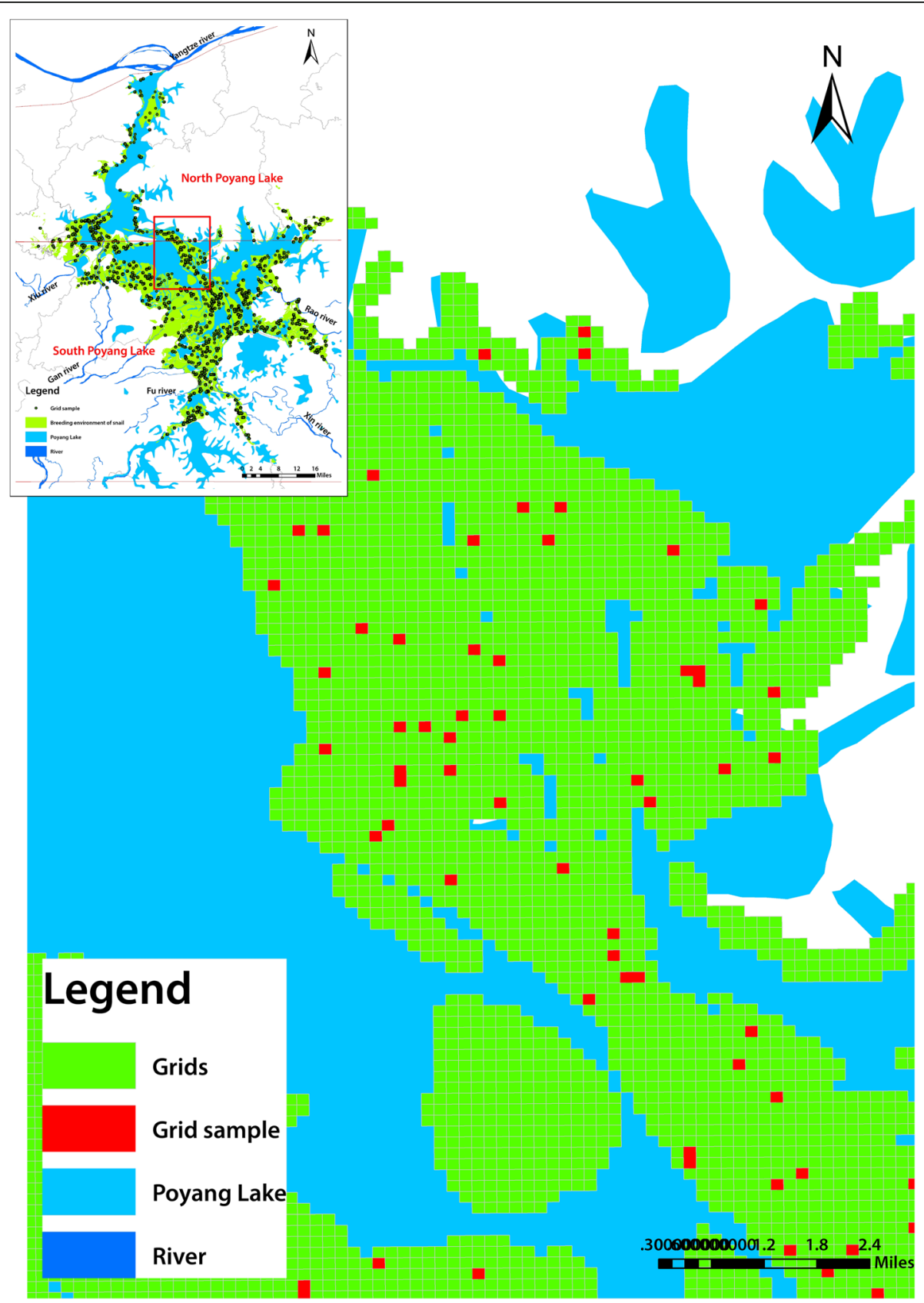

Fig. 2 Geographical spatial map of the $200 \times 200 \mathrm{~m}$ grids and sampling grid for snail survey (local magnified). The green squares represent vector girds created by ArcGIS software. The red ones represent sampling grids for snail survey 
frame were recorded. The collect snails were placed on a glass plate, covered by another glass plate, and the shells of snails were crushed slowly. A drop of water was added to each crushed snail. Those who had fresh soft tissue with a contractile response were considered living snails. The plate was then placed under a microscope or dissection microscope in order to identify a possible infection of Schistosoma japonicum.

\section{Processing of elevation data}

Based on the topographic map of Poyang Lake bottom in 2009, the Digital Elevation Model (DEM) grids of the topographic map were projected into the WGS-84 coordinate system and Transverse Mercator projection using the ArcGIS software. The DEM data is preprocessed before interpolation, which includes separating the conglutinated contour line and connecting the disconnected contour line, establishing the elevation index table at the same time, and then calculating the elevation data interpolation. The method of contour raster image profile interpolation was used for elevation data interpolation in Contour Line rendering. The elevation accuracy was evaluated by the checkpoint method and contour playback methodolgy. The elevation data corresponding to the spatial position of each surveyed snail frame was extracted by using the software tool of "Extract Values to Points".

\section{Data analysis}

All snail survey data were collected and statistically analyzed with SPSS 20.0 software (IBM, Armonk, USA). Two statistical indicators, percent of frames with living snails and mean density of living snails, were analyzed. Chi-squared test $\left(\chi^{2}\right)$ test was used to determine the percent of frames with living snail with $P<0.05$ considered as statistically significant. Considering the negative binomial distribution of Oncomelania hupensis snails and the number of snails in most survey frame being zero, a logarithmic variance analysis was used to analyze the mean density of living snail. Firstly, the number of snails in each survey frame plus one and the logarithm was taken. Then, the logarithmic arithmetic mean was calculated. After that, antilog minus one was taken. Finally, variance analysis was used to determine the mean density of living snail with $P<0.05$ considered as statistically significant. The formula for calculating the two indicators is as following:

percent of frames with living snail (\%)

$$
=\frac{\text { frames of living snail }}{\text { Number of investigated frames }} \times 100 \%
$$

$$
\begin{aligned}
& \text { mean density of living snail }\left(\mathrm{No} . / 0.1 \mathrm{~m}^{2}\right) \\
& =\lg ^{-1}\left(\frac{\sum \lg (\text { number of living snail }+1)}{\text { Number of investigated frames }}-1\right.
\end{aligned}
$$

The snail frame elevation was graded at 1 meter intervals, then, the percent of frames with living snails and the mean density of living snails at each elevation grade were calculated in the southern and northern sectors of the lake to determine snail-concentrated elevation intervals.

\section{Results}

\section{Snail survey}

A total of 1159 potential snail sampling grids were surveyed, of which 15231 frames were investigated. 1241 frames had live Oncomelania snails corresponding to $8.15 \%$ of the total number of frames. The mean density of live snails was $0.141 / 0.1 \mathrm{~m}^{2}$, with a maximum of 57 snails per frame $\left(0.1 \mathrm{~m}^{2}\right)$. The percent of frames with snails in the southern sector $(8.13 \%)$ of Poyang Lake did not differ statistically from the north (8.21\%). However, the mean density of live snails in the northern sector $\left(0.164 / 0.1 \mathrm{~m}^{2}\right)$ of the lake was statistically higher $(F=6.73 ; P=0.01)$ than the south $\left(0.141 / 0.1 \mathrm{~m}^{2}\right)$ (Fig. 3).

\section{Elevation of survey frames}

The data to determine elevation of each survey frame was extracted using a topographic map of the Poyang Lake bottom and was examined for abnormal values using the Box Diagram Method. There were a total 94 abnormal elevation values that were discarded from further statistical analysis. The frame elevation ranged from $10-16 \mathrm{~m}$, accounting for $97.7 \%$ of the total number of frames. The highest and lowest elevations were $19.7 \mathrm{~m}$ and $5 \mathrm{~m}$, respectively. The elevation of surveyed frames in the southern lake and the northern lake ranged from $9.0-19.7 \mathrm{~m}$ and $5.0-19.7 \mathrm{~m}$, respectively (Table 1 ).

\section{Elevation of frames with Oncomelania snails}

The elevation of snail frames ranged from $11.1 \mathrm{~m}$ to $15.8 \mathrm{~m}$ in the southern sector of the lake and from $9.3 \mathrm{~m}$ to $15.6 \mathrm{~m}$ in the north sector of the lake. As shown below in Table 2, the mean elevation of surveyed Oncomelania frames in the southern sector $(13.2 \mathrm{~m})$ of the lake was significantly higher $(F=215.2 ; P<0.01)$ than in the northern sector $(12.0 \mathrm{~m})$.

\section{Snail-concentrated elevation intervals}

In the southern sector of the lake, the elevation with the highest percentage of living snails was at $15-16 \mathrm{~m}$ (18.2\%), and secondly at $12-13 \mathrm{~m}(12.1 \%)$. In the north sector of the lake, the elevation range with highest percentage of living snails was at $15-16 \mathrm{~m}$ (14.3\%), and secondly at $12-14 \mathrm{~m}(11.5 \%)$. The mean density of living snails $\left(0.387 / 0.1 \mathrm{~m}^{2}\right)$ at an elevation of $15-16 \mathrm{~m}$ in the 


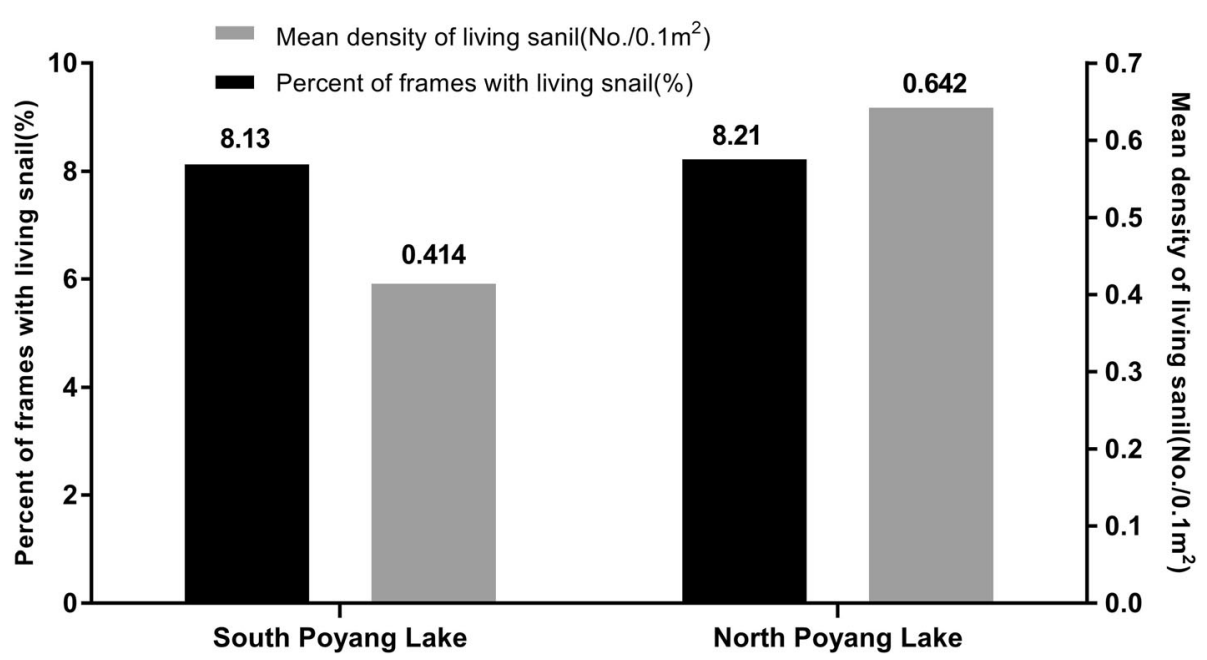

Fig. 3 Investigation of Oncomelania hupensis snails in different areas of Poyang Lake

southern lake was significantly higher $(F=129.6 ; P<0.01)$ than that of other elevations recorded in the sector. In the northern lake region, the mean density of living snails at an elevation of $12-14 \mathrm{~m}$ was $0.239 / 0.1 \mathrm{~m}^{2}$. This was again significantly higher $(F=20.8 ; P<0.01)$ than the other elevations recorded (Table 3 ).

\section{Discussion}

The vast marshlands of the Poyang Lake region are historically an endemic zone for zoonotic schistosomiasis in Jiangxi province. The marshlands surrounding Poyang
Lake are distributed over 13 counties. In the mid-1980s, based on elevations provided by the hydrological stations in the Poyang Lake region, maximum and minimum elevations of 615 marshlands were calculated and Oncomelania snails surveyed. The survey indicated that snails were distributed at 'three marshland belts' at an elevation 11-16 $\mathrm{m}$. The upper belt had few snail-infested areas, the middle belt was deemed snail-concentrated, while lower belt, like the upper belt, had few snails. Thus, $95 \%$ of the Oncomelania snail habitat in the lake region was distributed in marshlands at elevation

Table 1 Elevation of survey frames in the Poyang Lake region of China

\begin{tabular}{|c|c|c|c|c|c|c|c|c|c|c|c|c|}
\hline \multirow{2}{*}{$\begin{array}{l}\text { Elevation } \\
\text { grading (m) }\end{array}$} & \multicolumn{4}{|c|}{ South Poyang Lake } & \multicolumn{4}{|c|}{ North Poyang Lake } & \multicolumn{4}{|l|}{ Total } \\
\hline & Frequency & $\begin{array}{l}\text { Composition } \\
\text { ratio }(\%)\end{array}$ & $\operatorname{Max} .(\mathrm{m})$ & Min. (m) & Frequency & $\begin{array}{l}\text { Composition } \\
\text { ratio }(\%)\end{array}$ & $\operatorname{Max} .(m)$ & Min. (m) & Frequency & $\begin{array}{l}\text { Composition } \\
\text { ratio }(\%)\end{array}$ & $\operatorname{Max} .(\mathrm{m})$ & Min. (m) \\
\hline $5.0-5.9$ & & & & & 10 & 0.31 & 5.9 & 5.0 & 10 & 0.07 & 5.9 & 5.0 \\
\hline $6.0-6.9$ & & & & & 3 & 0.09 & 6.0 & 6.0 & 3 & 0.02 & 6.0 & 6.0 \\
\hline $7.0-7.9$ & & & & & 3 & 0.09 & 7.9 & 7.0 & 3 & 0.02 & 7.9 & 7.0 \\
\hline $8.0-8.9$ & & & & & 22 & 0.68 & 8.8 & 8.1 & 22 & 0.15 & 8.8 & 8.1 \\
\hline $9.0-9.9$ & 19 & 0.16 & 9.8 & 9.0 & 147 & 4.58 & 9.8 & 9.0 & 166 & 1.10 & 9.8 & 9.0 \\
\hline $10.0-10.9$ & 254 & 2.13 & 10.8 & 10.0 & 619 & 19.27 & 10.8 & 10.0 & 873 & 5.77 & 10.8 & 10.0 \\
\hline $11.0-11.9$ & 2030 & 17.02 & 11.9 & 11.0 & 1048 & 32.63 & 11.8 & 11.0 & 3078 & 20.33 & 11.9 & 11.0 \\
\hline $12.0-12.9$ & 3542 & 29.70 & 12.9 & 12.0 & 747 & 23.26 & 12.8 & 12.0 & 4289 & 28.33 & 12.9 & 12.0 \\
\hline $13.0-13.9$ & 2685 & 22.52 & 13.9 & 13.0 & 329 & 10.24 & 13.8 & 13.0 & 3014 & 19.91 & 13.9 & 13.0 \\
\hline $14.0-14.9$ & 2617 & 21.95 & 14.9 & 14.0 & 216 & 6.72 & 14.8 & 14.0 & 2833 & 18.72 & 14.9 & 14.0 \\
\hline $15.0-15.9$ & 660 & 5.53 & 15.8 & 15.0 & 42 & 1.31 & 15.8 & 15.0 & 702 & 4.64 & 15.8 & 15.0 \\
\hline $16.0-16.9$ & 69 & 0.58 & 16.8 & 16.0 & 14 & 0.44 & 16.7 & 16.0 & 83 & 0.55 & 16.8 & 16.0 \\
\hline $17.0-17.9$ & 28 & 0.23 & 17.8 & 17.0 & 5 & 0.16 & 17.7 & 17.0 & 33 & 0.22 & 17.8 & 17.0 \\
\hline $18.0-18.9$ & 20 & 0.17 & 18.8 & 18.0 & 5 & 0.16 & 18.7 & 18.0 & 25 & 0.17 & 18.8 & 18.0 \\
\hline $19.0-19.9$ & 1 & 0.01 & 19.7 & 19.7 & 2 & 0.06 & 19.7 & 19.1 & 3 & 0.02 & 19.7 & 19.1 \\
\hline 合计 & 11925 & 100.00 & 19.7 & 9.0 & 3212 & 100.00 & 19.7 & 5.0 & 15137 & 100.00 & 19.7 & 5.0 \\
\hline
\end{tabular}


Table 2 Elevation of Oncomelania surveyed frames in the Poyang Lake region of China

\begin{tabular}{|c|c|c|c|c|}
\hline \multirow[t]{2}{*}{ Area } & \multirow{2}{*}{$\begin{array}{l}\text { Number of } \\
\text { survey point }\end{array}$} & \multicolumn{3}{|c|}{ Elevation (m) } \\
\hline & & Mean & Median & Extremum \\
\hline South Poyang Lake & 973 & $13.2 \pm 1.1$ & 12.9 & $11.1-15.8$ \\
\hline North Poyang Lake & 263 & $12.0 \pm 1.2$ & 12.0 & $9.3-15.6$ \\
\hline
\end{tabular}

ranging from 12 to $15 \mathrm{~m}$. This snail-concentrated belt is typically submerged during the flood season from April to May, and reemerges after the water reced in October or November. There were virtually no snails $(<3 \%)$ in the marshlands at elevations below $11 \mathrm{~m}$ or at elevations greater than $16 \mathrm{~m}$ [25].

Snail distribution fluctuates with the water level. Water levels that are too high (flooding) or too low (drought) will affect the reproduction of snails [26]. In a study in 2013, Feng et al. reported that the average marshland area in Poyang Lake region increased significantly by $385.7 \mathrm{~km}^{2}$ in 2004-2009 (after the closure of the Three Gorges Dam) as compared with that in 20002002 (before dam closure) [27]. A comparison of water levels in Poyang lake between 1993 and 2012 found that the proportion of very low water level $(<10 \mathrm{~m}$; Wusong elevation) after 2003 had soared from 4.34 to $24.8 \%$, and the dry season after 2003 had lasted longer [28]. Thus, snail reproduction would have certainly been impacted. It was also observed that at this water level $(<10 \mathrm{~m})$ there was a change in snail distribution with more suitable snail environments situated further of north [29].

In this study, we investigated the distribution of Oncomelania snails in the Poyang Lake region using both GIS and GPS in order to ascertain the dynamic changes the snail distribution pattern at different elevations in the marshlands and to further define the snail habitat. A total of 1159 potential snail sampling grids were surveyed, of which 15231 frames $\left(0.1 \mathrm{~m}^{2} /\right.$ frame $)$ were investigated. 7049 frames had live Oncomelania snails corresponding to $8.15 \%$ of the total number of frames sampled. The mean density of living snails was 0.463 / $0.1 \mathrm{~m}^{2}$. The percent of frames with snails in the southern sector $(8.13 \%)$ of the Poyang Lake did not differ statistically from the north $(8.21 \%)$. However, the mean density of live snails in the northern sector $\left(0.164 / 0.1 \mathrm{~m}^{2}\right)$ of the lake was statistically greater than the south $\left(0.141 / 0.1 \mathrm{~m}^{2}\right)$. This finding was similar to that reported by $\mathrm{Hu}$ et al [29].

Historical data has shown that the elevation of snail-infested marshlands in Poyang Lake is at $10-16 \mathrm{~m}$, and predominately between 12 and $14 \mathrm{~m}$ [30]. The present distribution of snails in southern and northern sectors of Poyang Lake has changed significantly, and the snail-concentrated belts have also changed correspondingly. In the south sector of the lake, the snail-inhabited marshlands is distributed at $11-16 \mathrm{~m}$ and were divided two snail-concentrated belts (e.g., 12-13 m and $15-16 \mathrm{~m}$ of elevation). In the north sector of the lake, the snail-inhabited marshlands ranged from 9 to $16 \mathrm{~m}$ in elevation, with snail-concentrated belt at $12-14 \mathrm{~m}$. There are two possible reasons that may explain the difference in the density of snails between the south and north of Poyang Lake. Firstly, the elevations of all marshlands in the south of Poyang Lake are obviously higher than those in the north. In recent years, the dry season in autumn and winter in the lake advanced and extended. As a result the marshlands with high altitude were not flooded or rarely flooded, which had a negative effect on egg laying and hatching of snails. As a consequence the density of snails in the south was greatly reduced. In contrast, dynamic changes in the water level had less impact on the marshlands in the middle and low altitudes in the north of the lake. These marshlands are typically flooded in the spring, autumn and winter and are thus more suitable for snail breeding and reproduction, which lead to the increase or higher density of the snails. Secondly, with a sustained lower water level, the soil moisture content in the high elevation marshlands in the south of the lake were

Table 3 Snail-concentrated elevation intervals in the Poyang Lake region of China

\begin{tabular}{|c|c|c|c|c|}
\hline \multirow{2}{*}{$\begin{array}{l}\text { Elevation } \\
\text { grading }(\mathrm{m})\end{array}$} & \multicolumn{2}{|l|}{ South Poyang Lake } & \multicolumn{2}{|l|}{ North Poyang Lake } \\
\hline & $\begin{array}{l}\text { Percent of frames } \\
\text { with living snail (\%) }\end{array}$ & $\begin{array}{l}\text { Mean density of living } \\
\left.\text { snail (No./0.1 } \mathrm{m}^{2}\right)\end{array}$ & $\begin{array}{l}\text { Percent of frames } \\
\text { with living snail (\%) }\end{array}$ & $\begin{array}{l}\text { Mean density of living } \\
\text { snail }\left(\text { No. } / 0.1 \mathrm{~m}^{2}\right)\end{array}$ \\
\hline$<9.0$ & - & - & 0 & 0 \\
\hline $9.0-9.9$ & 0 & 0 & 3.40 & 0.079 \\
\hline $10.0-10.9$ & 0 & 0 & 8.72 & 0.185 \\
\hline $11.0-11.9$ & 3.79 & 0.056 & 6.87 & 0.116 \\
\hline $12.0-12.9$ & 12.06 & 0.205 & 10.31 & 0.229 \\
\hline $13.0-13.9$ & 7.49 & 0.125 & 11.55 & 0.263 \\
\hline $14.0-14.9$ & 5.62 & 0.085 & 5.09 & 0.098 \\
\hline $15.0-15.9$ & 18.18 & 0.387 & 14.29 & 0.178 \\
\hline$>16.0$ & 0 & 0 & 0 & 0 \\
\hline
\end{tabular}


reduced, making egg laying and hatching of snails difficult, which ultimately resulted in a decrease of snail density. At the same time, the low elevation swamp lands in the north of the lake has now evolved into grasslands, resulting in the increase of marshland area and the migration of snails down to the waterline. Consequently, both the area of snail-infested marshlands and snail density in the north of the lake increased. The lower snail-infested elevation of marshland in the southern lake was two meters higher than that in the northern lake, which indicated an eco-environment suitable for snail survival and that breeding was moving from the southern lake to lower elevated areas of the northern lake. Whether this trend of snail distribution in the marshland of Poyang Lake will continue and is caused by the Three Gorge Dam is yet to be fully determined. Previous studies have confirmed that the distribution of snail in the lake region is closely related to vegetation species in addition to elevation [31]. The relationship between the current snail distribution and vegetation needs further study in the future.

\section{Conclusions}

Oncomelania hupensis, the snail intermediate host of schistosomiasis in China, is distributed in the marshlands of Poyang Lake at an elevation of 9-16 m elevation and the distribution of snails has changed over time due to changes in the water level post closure of the Three Gorges Dam. The outcomes are important for national integrated schistosomiasis control strategies leading to disease elimination. Based on the current geological features of the snail habitant, focused mollusciciding should occur in northern regions within identified snail hotspots of transmission.

\section{Additional file}

Additional file 1: Multilingual abstracts in the five official working languages of the United Nations. (PDF 694 kb)

\section{Acknowledgments}

We thank Jiangxi Provincial Schistosomiasis and Endemic Diseases Control Office for its administrative support and the technical staff at Nachang Schistosomiasis Control Station, Xinjan Schistosomiasis Control Station, Jinxian Schistosomiasis Control Station, Gaoxin Schistosomiasis Control Station, Yugan Schistosomiasis Control Station, Poyang Schistosomiasis Station, Yongxiu Schistosomiasis Control Station, Gongqing Schistosomiasis Control Station, Lushan Schistosomiasis Control Station, Lianxi.

Schistosomiasis Control Station, Hukou Schistosomiasis Control Station, and Duchang Schistosomiasis Control Station for their assistance in the fieldwork.

\section{Funding}

This research was supported by the National Natural Science Foundation of China (grant No. 81660557, 71764011) and Jiangxi Province Focus on Research and Development Plan (grant No. 20171BBG70105).

\section{Availability of data and materials}

The dataset used in the study are available from the corresponding author on reasonable request.

\section{Authors' contributions}

DDL conceived of and designed research. FH, JG, SBL, ZJL, MY, ZC and YML performed the field snail survey. FH and JG did the analyses and co-wrote the paper. DDL, AR and YSL contributed to the writing and revisions. All the authors have read and approved the final manuscript.

\section{Ethics approval and consent to participate}

Not applicable.

\section{Consent for publication}

Not applicable.

\section{Competing interests}

The authors declare that they have no competing interests.

\section{Author details}

${ }^{1}$ Jiangxi Provincial Institute of Parasitic Diseases, No. 239, First Gaoxin Rd., Gaoxin District, 330096 Nanchang, Jiangxi Province, People's Republic of China. ${ }^{2}$ Molecular Parasitology Laboratory, Infectious Diseases Division, QIMR Berghofer Medical Research Institute, Brisbane, Australia. ${ }^{3}$ Menzies Health Institute Queensland, Griffith University, Gold Coast, QLD, Australia.

Received: 4 June 2018 Accepted: 12 March 2019

Published online: 29 March 2019

\section{References}

1. Zhou XN, Wang LY, Chen MG, Wu XH, Jiang QW, Chen XY, et al. The public health significance and control of schistosomiasis in China--then and now. Acta Trop. 2005;96(2-3):97-105

2. Zou L, Ruan SG. Schistosomiasis transmission and control in China. Acta Trop. 2015:143:51-7.

3. Zhou XN. Implementation of precision control to achieve the goal of schistosomiasis elimination in China. Zhongguo Xue Xi Chong Bing Fang Zhi Za Zhi. 2016;28(1):1-4 (in Chinese).

4. Zhang $\perp$, Xu ZM, Oian YJ, Dang H, Lv S, Xu J, et al. Endemic status of schistosomiasis in People's republic of China in 2015. Zhongguo Xue Xi Chong Bing Fang Zhi Za Zhi. 2017;29(6):669-77 (in Chinese).

5. Liu L, Yang GJ, Zhu HR, Lin A. Knowledge of, attitudes towards, and practice relating to schistosomiasis in two subtypes of a mountainous region of the People's republic of China. Infect Dis Poverty. 2014;3(1):16.

6. Hu Y, Xiong CL, Zhang ZJ, Luo C, Ward M, Gao J, et al. Dynamics of spatial clustering of schistosomiasis in the Yangtze River valley at the end of and following the World Bank loan project. Parasitol Int. 2014;63(3):500-5.

7. Tseng KH, Liang S, Ibaraki M, Lee H, Shum CK. Study of the variation of schistosomiasis risk in Lake Poyang in the People's republic of China using multiple space-borne sensors for monitoring and modelling. Geospat Health. 2014;8(2):353-64.

8. Li YS, Raso G, Zhao ZY, He YK, Ellis MK, McManus DP. Large water management projects and schistosomiasis control, Dongting Lake region, China. Emerg Infect Dis. 2007;13(7):973-9.

9. Hao Y, Wu XH, Zhen H, Wang LY, Guo JG, Xia G, et al. Schistosomiasis situation in People's Republic of China in 2006. Zhongguo Xue Xi Chong Bing Fang Zhi Za Zhi. 2007;19(6):401-4 (in Chinese).

10. Liu YB, WU GP, Zhao XS. Recent declines in China's largest freshwater lake: trend or regime shift? Environ Res Lett. 2013:8:014010.

11. Du YL, Zhou HD, Peng WQ, Liu ZB, Wang SY, Yin SH. Modeling the impacts of the change of river-Lake relationship on the hydrodynamic and water quality revolution in Poyang Lake. Acta Sci Circumstant. 2015;35(5):1274-84 (in Chinese).

12. Liu XD, Ren BF. Analysis on variation characteristics and genesis of lower water level of Poyang Lake. Yangtze River. 2014;45(4):12-6 (in Chinese).

13. Chen HG, Zeng XJ, Lin DD, Lv SB, Gu XN, Hang CQ, et al. The changes of hydrological regime in Poyang Lake after runs of three gorges project and its impact on prevalence of schistosomiasis in the lake region. Zhongguo Xue Xi Chong Bing Fang Zhi Za Zhi. 2013;25(5):444-50 (in Chinese).

14. Wang XY, He J, Yang K, Liang S. Applications of spatial technology in schistosomiasis control programme in the People's Republic of China. Adv Parasitol. 2016:92:143-63.

15. Li FY, Ma SJ, Li YY, Tan HZ, Hou XY, Ren GH, et al. Impact of the three gorges project on ecological environment changes and snail distribution in Dongting Lake area. PLoS Negl Trop Dis. 2017;11:e0005661. 
16. Zhu HR, Liu L, Zhou XN, Yang GJ. Ecological model to predict potential habitats of Oncomelania hupensis, the intermediate host of Schistosoma japonicum in the mountainous regions, China. PLoS Negl Trop Dis. 2015;9:e0004028.

17. Wang $Y$, Zhuang DF. A rapid monitoring and evaluation method of schistosomiasis based on spatial information technology. Int I Environ Res Public Health. 2015;12:15843-59.

18. Wei ZH, Li YK, Xu P, Qian FW, Shan JH, Tu XB. Patterns of change in the population and spatial distribution of oriental white storks (Ciconia boyciana) wintering in Poyang Lake. Zool Res. 2016;37(6):338-46.

19. Zhang $Z X$, Chen $X, X u C Y$, Hong $Y$, Hardy J, Sun ZH. Examining the influence of river-Lake interaction on the drought and water resources in the Poyang Lake basin. J Hydrol. 2015;522:510-21.

20. Feng L, Hu C, Chen X. Satellites capture the drought severity around China's largest freshwater lake. IEEE J STARS. 2012;5(4):1266-71.

21. Hong F, Chen WJ, Zhou HM, Chen JS. Discussion on impact of Poyang Lake ecological water control project on aquatic biology. Jiangxi Sci. 2010;28(4): 555-8 (in Chinese).

22. Lu JY, Yao SM, Shao XJ, Zhang XB. Response process of the lower reaches of the three gorges dam after the initial operation. Beijing: Science Press; 2012. (in Chinese)

23. Hu F, Lin DD, Yuan M, Liu YM, Li ZJ, Li JY. Study on the digital mapping of Oncomelania snails in marshland of Poyang Lake region based on GIS. Jiangxi Med J. 2014;49(9):809-11+826 (in Chinese).

24. Chen Z, Gu XN, Lv SB, Li YF, Jiang WS, Hang CQ, et al. Endemic situation of schistosomiasis in the national surveillance sites in Jiangxi Province from 2005 to 2014. J Trop Dis Parasitol. 2015;13(4):193-6 (in Chinese).

25. Zhang SJ, Liu ZD, Li GH, Zhong JH, Chen Y. Study on snail condition investigation and snail control measures in Poyang Lake area. Yi Xue Yan Jiu Tong Xun. 1988;17(9):27-8 (in Chinese).

26. Chen HG, Lin DD. The prevalence and control of schistosomiasis in Poyang Lake region, China. Parasitol Int. 2004;53(2):115-25.

27. Feng L, Hu C, Chen X, Zhao X. Dramatic inundation changes of China's two largest freshwater lakes linked to the three gorges dam. Environ Sci Technol. 2013:47:9628-34.

28. Mei XF, Dai ZJ, Du JZ, Chen JY. Linkage between three gorges dam impacts and the dramatic recessions in China's largest freshwater Lake, Poyang Lake. Sci Rep. 2015;5:18197.

29. Hu F, Liu YM, Li ZJ, Yuan M. Effect of environmental factors on temporal and spatial distribution of schistosomiasis in Poyang Lake region. Zhongguo Xue Xi Chong Bing Fang Zhi Za Zhi. 2012;24(4):393-6+403 (in Chinese).

30. Zhang B. Studies on Poyang lake. Shanghai: Shanghai Scientific \& Technical Publishers; 1988. p. 17-8. (in Chinese)

31. Li ZJ, Chen HG, Gong P, Zeng XJ, Liu YM, Xie SY. Study on relationship between vegetation and spatial distribution of Oncomalania snail in Poyang Lake region. Zhongguo Xue Xi Chong Bing Fang Zhi Za Zhi. 2010;22(2):1325 (in Chinese).

Ready to submit your research? Choose BMC and benefit from:

- fast, convenient online submission

- thorough peer review by experienced researchers in your field

- rapid publication on acceptance

- support for research data, including large and complex data types

- gold Open Access which fosters wider collaboration and increased citations

- maximum visibility for your research: over $100 \mathrm{M}$ website views per year

At $\mathrm{BMC}$, research is always in progress.

Learn more biomedcentral.com/submissions 